\title{
The effects of locus of control on procrastination among undergraduates: the coping strategy as a mediator
}

\author{
Poh Chua Siah*, Hui Qin Ang, Siew Man Chan, Ee Leng Wong \\ Universiti Tunku Abdul Rahman, Kampar Campus, Malaysia
}

\begin{abstract}
Procrastination is a common issue among undergraduate students. Studies have found that locus of control and coping strategies are associated with procrastination, and the relationships between locus of control and coping strategies. However, no study has examined the relationships among these three factors. This study aims to use the personality-coping-outcome theory as a framework to examine whether the coping strategy is a mediator for the effects of locus of control on procrastination. One hundred and fifty undergraduates were recruited by using the purposive sampling method. A crosssectional survey was used to collect data. The results showed that those participants with a higher internal locus of control are less likely to procrastinate when the problem-solving coping strategy is adopted. These findings suggested that a firm belief of controlling over one life episode does not necessarily change the procrastination. Programs can be designed to improve undergraduates' understanding of adopting effective strategies to cope with their procrastination.
\end{abstract}

Keywords: Locus of control; procrastination; coping strategies; problem solving; avoidance; positive thinking; social support

\section{Introduction}

Procrastination is a voluntary, irrational and unnecessary delay of an intended course of actions without acknowledging that this postponement will bring along subjective discomfort and negative outcomes (Steel, 2007). Procrastination that happens in the academic area is regarded as academic procrastination (Jiao et al., 2011). Academic procrastination has become a common occurrence in nowadays societies and is usually found in delay at writing research papers, prolonging to study for their exam, and postpone to review their weekly assignment (Onwuegbuzie, 2004; Steel, 2007).

The prevalence of academic procrastination among undergraduates is high. For example, Saplavska and Jerkunkova (2018) reported that $48 \%$ of undergraduate students at a university in Latvia have the problems of academic procrastination that students often finish their tasks at the last minute. He (2017) also reported that $34 \%$ of undergraduates, $43 \%$ of master students and $44 \%$ of $\mathrm{PhD}$ students at a university in the United Kingdom suffered from academic procrastination. Bakar and Khan (2016) reported that $79 \%$ of undergraduates in the Johor state of Malaysia could either be categorized as procrastinators or severe procrastinators.

The academic procrastination has drawn the attention of educators and policymakers since different negative consequences of academic procrastination have been reported. In terms of physical health, Tice and Baumeister (1997) reported that procrastinators might experience physical illness. Sirois (2007) suggested that procrastination can be linked to stress-related acute health issues such as lack of sleep, headaches, having flu or poor digestive problems. Besides, Sirois, Eerde and Argiropoulou (2015) also reported that students with procrastination problem might experience poor sleep quality due to the needless continual waking from the whole

* Corresponding author. Tel.: +60-05-4688888-2224

E-mail address: siahpc@utar.edu.my 
night, and found it difficult to sleep again and thus they feel unrested after waking in the morning.

The negative consequences of academic procrastination in mental health and academic performance were also reported. For example, Beutel et al. (2016) revealed that procrastination shows negative relationships with psychological well-being and mental health such as increased stress and anxiety levels, that the intentionally delaying action can create a feeling of discomfort and unease, which may lead to procrastinators experiencing persistent feeling anxious, stress and tiredness. Duru and Balkis (2017) recruited 348 undergraduate students in Turkey, and they found that students' procrastination is associated with low self-esteem, academic achievement and well-being. Morris and Fritz (2015) conducted a survey among 107 undergraduates from a university in the United States, and they reported a significant association between high procrastination levels and low coursework marks.

Academic procrastination can be relevant to personality. Makola (2014) conducted a literature review and suggested the negative association between sense of meaning and academic procrastination. Zhang et al. (2018) recruited 1184 undergraduate students in China and found that academic procrastination was negatively associated with a person's self-regulation ability. Popoola (2005) suggested that procrastination is a person's habit of putting their responsibilities off to the last minute, and thus procrastination can be regarded as a failure of self-regulation. Siah et al. (2019) also found the negative associations between grit personality and procrastination among Malaysia undergraduates.

Locus of control (LOC) is a personality that has been examined with its relationship to academic procrastination (Atibuni et al., 2017; Carden et al., 2004; Prihadi et al., 2018). LOC is the tendency to which people believe that they have control over their life episode throughout their whole life (Rotter, 1966). LOC has been specified into an internal or external locus of control. People with a high internal LOC believe that their behaviours and actions mostly contribute to their life events whereas people high in an external LOC tend to believe that external factors such as fate, luck and people are contributing to their life events (Rotter, 1966).

Most studies reported negative associations between internal LOC and academic procrastination and positive associations between external LOC and academic procrastination. For example, Kurtovic, Vukovic and Gajic (2018) surveyed 418 university students from Croatia. They found that lack of control leads students to feel more anxious and helpless, which result in a decline of academic motivations. Atibuni et al. (2017) recruited 203 university students at a public university in Uganda. They stated that internal LOC would lead to positive academic attitude, and external LOC students are found to have negative academic attitude moderately. Carden et al. (2004) recruited 114 undergraduate students from a private university in the southeast, and they found that students who score higher internal LOC score low in procrastination while compared to those students who score higher external LOC score. Popa (2012) recruited 174 Romanian high-school and they found that students who possessed higher internal LOC are have higher level of school achievement. less likely to have the problems of academic procrastination. They explained that

Nonetheless, some studies reported inconsistent results. Boysan and Kiral (2017) found out that there was no significant relationship between procrastination and LOC among the sample of 242 university students with an age range of 18 to 32 in Turkey. Similarly, Ferrari, Parker and Ware (1992) also revealed that no significant relationship between LOC and procrastination among 319 college students in the northeast area.

By using the personality-coping-outcome theory proposed by Gallagher (1996) as a framework, we assume that a possible reason for the inconsistent results of LOC and procrastination is related to the strategy they use. The personality-coping-outcome theory proposed that when one encounters stressful situations, personality influences one's coping style differently, which in turn further affects one's adjustment. Coping strategy refers to cognitive and behavioural endeavours to regulate internal and external requirements that exceed assessed personal resources (Lazarus \& Folkman, 1984). According to Parker and Endler (1992), specific coping strategies can mitigate 
stress and facilitate positive psychological consequences, while others aggravate stress and facilitate negative psychological consequences.

Coping strategies are usually classified as adaptive and maladaptive coping strategies. Adaptive coping strategies are defined as implementing action and searching for the resources to handle the issue (Lazarus \& Folkman, 1984). Conversely, maladaptive coping strategies are used to escape from the negative sentiments immediately initiated by the stressor as a method for recapturing control, without essentially addressing the origin of the stress (Lazarus \& Folkman, 1984). Chun Chu and Choi (2005) indicated that adaptive coping strategies include taskoriented coping strategies that enable to decrease stress by concentrating on current issues and emotional-oriented coping strategies that are the actions to reduce the emotional distress that is prompted by the stressors. Maladaptive coping strategies include avoidance-oriented coping strategies that overlook an issue or diverting oneself from it.

Some researchers have examined the relationships between coping strategies with academic procrastination. Sirois and Pychy (2013) suggested that procrastinators are best recognized by people who first emphasize short-term emotional regulation rather than long-term achievement. Thus academic procrastinators are more likely to use maladaptive strategies to cope with short-term emotional stress.

Sirois and Kitner (2015) conducted a study among 1003 undergraduate students, and they found that procrastinators used maladaptive coping strategies as their way of escaping from negative emotions in a short-term period. Similarly, Ferrari and DíazMorales (2014) conducted a research among 104 students from Spain university and found that chronic procrastinators participate in less constructive and positive behaviours that might regulate their mental health coping styles and adjustment. Also, Gareau, Chamandy, Kljajic and Gaudreau (2019) recruited 258 students from a Canadian university and found that students with higher levels of academic procrastination are more likely to use disengagement-oriented coping strategies and ultimately leads to lower levels of academic achievement.

Besides the relationships between coping strategies and procrastination, the relationships between LOC and coping have also been investigated. Demir, Demir, Bulut and Hisar (2014) conducted a study about nursing students through the commencing of a mentoring program where it helps to increase the adaptability of students. They aimed to evaluate students' way of coping with stress and LOC. Results showed that after entering the mentoring program, nursing students who are high in external LOC were switched into internal LOC. At the same time, the use of problem-focused coping was also increased when students shifted from external to internal LOC. Similar results were reported by Scott et al. (2010), who recruited 208 undergraduate students in Florida that have experienced hurricanes that happened around Florida in 2004. Results indicated that external LOC are significantly positively correlated with higher levels of avoidant coping behaviour. Also, Arslan, Dilmac and Hamarta (2009) recruited 514 Turkish university students, and they found that internal LOC undergraduate students used less avoidant coping but more problem-focused coping. Moreover, Kazemi et al. (2015) in Iran recruited 130 volleyball young men and found that internal LOC is significantly positively correlated with problem-focused coping.

\section{Methodology}

\subsection{Objective}

Since LOC is found to be associated with coping strategies and procrastination, and coping strategies are also found to be associated with procrastination, these findings may indicate possible relationships among LOC, coping strategies and procrastination. However, in our knowledge, no study has investigated the relationships among LOC, coping strategies and procrastination together. Accordingly, by using the personality-coping-outcome theory as a framework, we aim 
to examine the mechanism among their relationships, and we predict that coping is a mediator for the effects of LOC on academic procrastination.

The research questions, hypotheses and conceptual framework are as follows:

RQ 1. What are the relationships between LOC and coping strategies?

$\mathrm{H}_{1}$ a: internal LOC is positively associated with adaptive coping strategies (positive thinking, problem-solving and social support)

$\mathrm{H}_{1}$ b: internal LOC is negatively associated with maladaptive coping strategies (avoidance)

RQ 2. What are the relationships between coping strategies and academic procrastination?

H2a: Adaptive coping strategies (positive thinking, problem-solving and social support) are positively associated with academic procrastination

$\mathrm{H} 2 \mathrm{~b}$ : maladaptive coping strategies (avoidance) is negatively associated with academic procrastination

RQ 3. What are the relationships between LOC and academic procrastination?

H3: Internal LOC is negatively associated with academic procrastination

RQ 4. Whether coping strategies are the statistical mediators for the effects of LOC on procrastination?

H4: coping strategies are statistical mediators for the effects of internal LOC on academic procrastination.

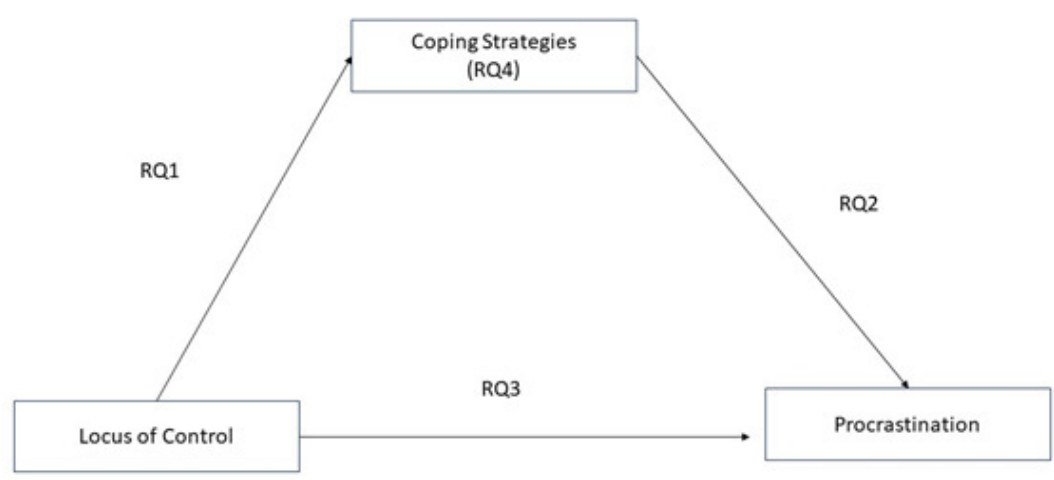

Figure 1. Conceptual framework

\subsection{Participants}

Two hundred participants at a university were recruited as respondents. The total valid sample was 150 after the screening of data. The sample size is larger than the minimum number of 92 samples based on the calculation of $\mathrm{G}^{*}$ power version 3.0 (five predictors, effect size is set at .15, and power is at .8). The final sample included 50 males $(33.3 \%)$ and 100 females $(66.7 \%)$. The age range of respondents is from 19 to 27 years old $(\mathrm{M}=21.49, \mathrm{SD}=1.34)$. 


\subsection{Instrument}

The questionnaire consists of four sections: demographic information, and three scales to measure LOC, coping strategies and academic procrastination.

Demographic Information: Participants were asked to fill in their ages and gender in this section.

Locus of Control: Internal and External LOC Scale, known as the I-E scale is a forced-choice test with a total of 29-items (Rotter, 1966) to test the internal or external LOC of an individual. Six items are filler questions to make the purpose of the scale ambiguous. There are two choices in each question. A higher total summation score from the 23-items indicated the participant is more external locus of control, and a lower total summation score indicated the participant is more internal LOC (Rotter, 1966). An example of external locus control response is "Many of the unhappy things in people's lives are partly due to bad luck", and an example of internal locus control response is "People's misfortunes result from the mistakes they make". This I-E scale is found to have an acceptable test-retest reliability and construct validity (Craig et al., 1984).

Brief COPE: Brief COPE is a 28 -item multidimensional scale to measure various coping strategies or regulate cognition for the stressors (Carver, 1997). Each question is rated on the 4-point Likert scale ( $1=\mathrm{I}$ haven't been doing this at all, $4=\mathrm{I}$ 've been doing this a lot). According to the findings of Baumstarck et al. (2017), this 28-item of Brief COPE consists of four factors: Problem-solving (four items), avoidance (10 items), positive thinking (six items) and social support (eight items). Sample items for the four factors are "I've been trying to come up with a strategy about what to do" (problem-solving), "I've been using alcohol or other drugs to help me get through it" (avoidance), "I've been learning to live with it" (positive thinking), and "I've been getting comfort and understanding from someone" (social support).

Tuckman Procrastination Scale: This scale comprised 16-items and was developed by Tuckman (Tuckman, 1991). The items are measured by using a 4-point Likert scale (" $1=$ that's not me, for sure", " 2 = that's not my tendency", " $3=$ that's my tendency","4= that's me for sure"). The Cronbach alpha reliability coefficient of this scale was 0.90 (Tuckman, 1991). This scale involves reversed items which are items $7,12,14,16$. A higher mean score indicates that the participant is more likely to have the problem of academic procrastination. A sample item is "I manage to find an excuse for not doing something".

\subsection{Procedure}

After getting approval from the scientific and ethical committee of the university (U/SERC/236/2019), purposive sampling was used to recruit participants that only those who are undergraduates were invited. The paper-and-pencil questionnaires were distributed at different locations at the campus, including lecture halls, tutorial room, cafeteria and library. When an undergraduate is approached, the purpose of the study was introduced first. Those undergraduates who agreed to participate were requested to sign in an informed consent form that includes the information of the survey, their right of not participating, and the confidentiality of the data they provided. The questionnaire requires approximately 10 to 15 minutes to complete. Once the questionnaire was completed, participants were asked to fold the questionnaire and put into an envelope and sealed, so that the content of questionnaires are only accessible by researchers. Researchers returned 15 minutes after to collect back the envelope.

\subsection{Data analysis}

The data was then keyed in an excel file. Both the SPSS and SmartPLS programs were used to analyze the data. Descriptive analyses were analyzed by the SPSS 
program, and the partial least structural equation model was analyzed by the SmartPLS program.

\section{Results}

\subsection{Data Cleaning}

Skewness and kurtosis were used to examine the normality of LOC, coping strategies (problem-solving, avoidance, positive thinking, and social support) and procrastination. The results showed that the values of the skewness for LOC was .066, -.03 for problem-solving coping strategy, -.05 for avoidance coping strategy, .11 for positive thinking coping strategy, -.16 for social support coping strategy, and .11 for procrastination. Besides, the values of kurtosis for LOC was -.32 , .06 for problem-solving coping strategy, -.49 for avoidance coping strategy, -.21 for positive thinking coping strategy, and -.33 for the social support coping strategy, and .22 for procrastination. The skewness and kurtosis values of all measurements were in the range between -2.0 and +2.0 (Kim, 2013), so the normality of the data for all measurements are acceptable.

\subsection{Measurement Model}

Construct Reliability: Some items in avoidance, positive thinking and social support scales were removed as their composite reliabilities are below the recommended values of .7 (Hair Jr et al., 2016). The final composite reliability of the measurements after removing these items ranged from .71 to .82 (Table 1). Correspondingly, the findings suggested that the latent constructs of all measurements are acceptable.

Table 1. Construct reliability and validity of all measurements

\begin{tabular}{lllll}
\hline Factors & Total item & & Item removed & \multicolumn{2}{l}{ Composite Reliability } \\
\cline { 2 - 3 } & & & $\underline{\text { Before }}$ & $\begin{array}{l}\text { After item } \\
\text { removed }\end{array}$ \\
\hline Locus of Control & 29 & 0 & 1 (a summation & \\
Avoidance & 10 & 1 & .62 & .71 \\
Positive Thinking & 6 & 2 & .39 & .79 \\
Problem Solving & 4 & 0 & .78 & .74 \\
Social Support & 8 & 2 & .51 & \\
Procrastination & 4 & 0 & .88 & \\
& & & & \\
\hline
\end{tabular}

Discriminant Validity: The Fornell-Larcker criterion was used to examine the discriminant validity of the measurements. As all the indexes of other measurements are lower than the square root of the measurement, the discriminant validity of the measurements is acceptable (see Table 2) (Hair Jr et al., 2016). 
Table 2. Discriminate validities of all measurements

$\begin{array}{lllll}1 & 2 & 3 & 4 & 5\end{array}$

1. Locus of Control

2. Avoidance

3. Positive Thinking

4. Problem Solving

5. Social Support

6. Procrastination
.13

$-.21$

$-.19$

$-.15$

.17
.51

$-.16 \quad .69$

$-.21 \quad .53$

.69

.27

.59

$.43-.12-.31$

.004

Coefficient of Determination, Effect Size and Collinearity Statistics of Measurements: The results of the analyses were shown in Table 3. As the variance inflation factor of all scales were also below 5, which indicate no collinearity issue was found (Hadi et al., 2016). Besides, the results also reveal a medium effect size of the predictors on procrastination (Sullivan \& Feinn, 2012), and the main effect size among the predictors is from the avoidance coping strategy.

Table 3. Coefficient of determination $\left(\mathrm{r}^{2}\right)$, effect size $\left(\mathrm{f}^{2}\right)$ and collinearity statistics (VIF) of measurements

\begin{tabular}{llccc}
\hline Exogenous & Endogenous & $\mathrm{R}^{2}$ & $\mathrm{f}^{2}$ & VIF \\
\hline Avoidance & Locus of Control & .02 & .02 & 1.00 \\
Positive thinking & Locus of Control & .04 & .04 & 1.00 \\
Problem solving & Locus of Control & .03 & .04 & 1.00 \\
Social support & Locus of Control & .02 & .02 & 1.00
\end{tabular}

Procrastination

$\begin{array}{lll}\text { Avoidance } & .18 & 1.06 \\ \text { Positive thinking } & .01 & 1.57 \\ \text { Problem solving } & .08 & 1.56 \\ \text { Social support } & .003 & 1.17 \\ \text { LOC } & .01 & 1.07\end{array}$

.28

\subsection{Structural Model}

As shown in Table 4, after controlling gender and age, internal LOC is associated with positive thinking and problem-solving, ps $=.01$, one-tailed, but is not significantly associated with avoidance and social support coping strategies, $\mathrm{ps}=.14$, one-tailed. Besides, avoidance coping strategy is positively associated with 
procrastination, $\mathrm{p}<.001$, one-tailed, but problem-solving is negatively associated with procrastination, $\mathrm{p}=.001$, one-tailed.

Table 4. Results of the Structural Equation Modelling

\begin{tabular}{|c|c|c|c|c|c|}
\hline \multicolumn{5}{|l|}{ Coping strategies } & P Values* \\
\hline LOC $\rightarrow$ Positive thinking & H1a & -.21 & .08 & 2.55 & .01 \\
\hline LOC $\rightarrow$ Problem solving & H1a & -.19 & .08 & 2.44 & .01 \\
\hline LOC $\rightarrow$ Social support & H1a & -.15 & .14 & 1.07 & .14 \\
\hline LOC $\rightarrow$ Avoidance & $\mathrm{H} 1 \mathrm{~b}$ & .13 & .12 & 1.09 & .14 \\
\hline \multicolumn{6}{|l|}{ Procrastination } \\
\hline Positive thinking $\rightarrow$ Procrastination & $\mathrm{H} 2 \mathrm{a}$ & .11 & .13 & .88 & .19 \\
\hline Problem solving $\rightarrow$ Procrastination & $\mathrm{H} 2 \mathrm{a}$ & -.29 & .09 & 3.13 & .001 \\
\hline Social support $\rightarrow$ Procrastination & $\mathrm{H} 2 \mathrm{a}$ & .05 & .13 & .41 & .34 \\
\hline Avoidance $\rightarrow$ Procrastination & $\mathrm{H} 2 \mathrm{~b}$ & .37 & .09 & 4.20 & $<.001$ \\
\hline LOC $\rightarrow$ procrastination & $\mathrm{H} 3$ & .09 & .08 & 1.27 & .11 \\
\hline \multicolumn{6}{|l|}{$\underline{\text { Mediating Effect }}$} \\
\hline LOC $\rightarrow$ Positive thinking $\rightarrow$ Procrastination & $\mathrm{H} 4$ & -.02 & .03 & .81 & .21 \\
\hline LOC $\rightarrow$ Problem solving $\rightarrow$ Procrastination & $\mathrm{H} 4$ & .05 & .03 & 1.88 & .03 \\
\hline LOC $\rightarrow$ Social support $\rightarrow$ Procrastination & $\mathrm{H} 4$ & -.01 & .02 & .36 & .36 \\
\hline LOC $\rightarrow$ Avoidance $\rightarrow$ Procrastination & $\mathrm{H} 4$ & .05 & .05 & 1.06 & .14 \\
\hline \multicolumn{6}{|l|}{$\underline{\text { Control variables }}$} \\
\hline Gender & & .03 & .08 & .44 & .33 \\
\hline Age & & -.15 & .07 & 2.03 & .02 \\
\hline
\end{tabular}

Note: * one-tailed test

\subsection{Mediating Effect}

As shown in Table 4, the specific indirect effects of LOC on procrastination through problem-solving coping strategy is significant, $\mathrm{p}=.03$, which indicated a statistically mediating effect. Besides, since the direct effect of LOC on procrastination is not significant, $\mathrm{p}=.11$, which indicates an indirect only mediating effect (Zhao et al., 2010). In other words, high LOC participants are more likely to use problem-solving coping strategy, and this coping strategy reduces their procrastination.

\section{Discussions}

Academic procrastination is a common problem among undergraduates, so it is essential to find out factors that associate with academic procrastination so that preventive strategies can be designed and implemented to assist undergraduates in adjusting better in their studies. As studies have found the associations between LOC and procrastination, between LOC and coping strategies, and between coping strategies and procrastination, these associations suggest a mechanism that links the three variables together. Nonetheless, in our knowledge, no study has been conducted to examine this mechanism that links the relationships among the three variables. 
Accordingly, the personality-coping-adaptation theory was used as a framework to examine this issue. Based on the theory, we expected that not only there are significant associations among these three variables, but also the coping strategies statistically mediate the effects of LOC on procrastination.

The results partially support our first hypothesis. In this study, the findings showed that internal LOC is associated with positive thinking and problem solving, but not associated with social support and avoidance. The results were consistent with the findings of a study conducted by Arslan, Dilmac and Hamarta (2009), who found that internal LOC people tend to use more problem-focused coping strategies than external LOC, and no difference was found between internal and external LOC in avoidance and social support. Also, the findings are consistent with the findings reported by DeMello and Imms (1999) that internal LOC was associated with productive problem solving, and the findings of Leontopoulou (2006) that LOC is positively correlated with active coping but not with avoidance coping.

However, the results did not support the hypothesis that internal LOC would seek social support to cope with their procrastination and the hypothesis that internal LOC would be less likely to use avoidance strategy to cope with their problems. These unsupported findings can be because Internal LOC prefers to take an active strategy to cope with the problems, and thus no significant association was found between LOC and the use of social support and avoidance coping strategies, which relatively are passive.

The results also partially support the second hypothesis. The results showed that problem-solving is negatively associated with procrastination and avoidance is positively associated with procrastination, but no significant association was found between positive thinking and social support coping strategies on procrastination. The findings that problem-solving is negatively associated with academic procrastination was consistent with other studies. For example, Yurtseven and Dogan (2019) found that students who have higher problem-solving coping strategies are inclined to procrastinate less. Shahram (2011) found that poor problem-solving coping strategy is one of the reasons that lead to procrastination. The findings that avoidance coping strategy is positively associated with academic procrastination was also consistent with other studies. For example, Kandemir, İlhan, Özpolat, and Palanc1 (2014) reported that students who use the avoidance coping strategy to cope with the stress result in more academic procrastination.

However, the findings of the current study did not find a significant relationship between positive thinking and procrastination, as reported by other studies. For example, Moradi, Rashidi, and Golmohammadian (2017) who stated that the positive thinking coping strategy could result in less procrastination since positive thinking helps students to emphasize on their capability and reduce their view at their weakness which assists them to accept their responsibilities thus procrastination was lessened. Besides, the finding of the insignificant relationship between social support coping strategies and procrastination was also inconsistent with the finding of Tuasikal and Patria (2019) who found that social support has a negative correlation with procrastination. A possible explanation of the inconsistency is that both positive thinking and social support coping strategies are not directly related to the actions needed to reduce the academic procrastination. Positive thinking and social support may provide a buffer to reduce the negative impacts of procrastination, but using these two coping strategies without taking action could still be a problem for procrastination.

The result did not find a significant association between LOC and procrastination. These findings are inconsistent with some studies. For example, Prihadi et al. (2018) stated that people with more internal LOC tend to procrastinate less because they take more responsibilities over their events and life, and these students will blame themselves for any procrastination as they believe that everything is under their control. Gargari, Sabouri and Norzad (2011) also stated that external LOC students tend to attribute their outcome to the external factors which made them more often postpone their academic tasks, such as luck or fate or task difficulty. Nonetheless, the inconsistency results are understandable based on the personality-coping-outcome 
theory (Gallagher, 1996), as the effects of personality on procrastination is relevant to the coping strategies adopted.

The results also partially support the fourth hypothesis. The findings showed that coping strategies did mediate the effects of LOC on procrastination, but only for the problem-solving coping strategy. In other words, only those internal LOC participants who use problem-solving coping strategy are less likely to procrastinate. These findings are consistent with the conceptual definition of LOC, which suggests that internal LOC individuals believe that their behaviours and actions mostly contribute to their life events (Rotter, 1966). While comparing to the positive thinking, social support and avoidance coping strategies, problem-solving is a more direct link to the action, and thus LOC who use the problem-solving strategy is more likely to take action to reduce procrastination.

In conclusion, the findings are consistent with the predictions of the personalitycoping-outcome theory. Even Though problem-solving and positive thinking are found to be associated with internal LOC, and both the problem-solving and avoidance are found to be associated with procrastination, it is the problem-solving strategy that links between LOC and procrastination. In other words, the reason that internal LOC participants are less likely to procrastinate as they use the problemsolving strategy, and those internal LOC participants who use other strategies to cope their procrastination do not have such effect.

Nonetheless, the interpretation of the findings needs to be cautioned. Since the participants of this study were only recruited from a university, the results may not be able to generalize to undergraduates at other universities. More studies that recruit undergraduates from different universities would be necessary to examine the robustness of the study. Besides, the study is a cross-sectional design and uses the statistical techniques of SEM to examine the statistical mediating effect, which should be cautious while giving the cause and effect explanation, as no real time-order difference was examined. Future study may consider using a longitudinal or a successive design to examine the robustness of the mediating effect.

The findings of this study may provide some practical and theoretical implications. In terms of practical implications, counsellors may provide workshops or programs to let undergraduates to aware the importance of coping strategies, that the procrastination is not relevant to a personality that is hard to change, procrastination can be reduced if an appropriate coping strategy has been adopted. In terms of theoretical implications, this study has filled in the literature gap about the relationships among LOC, coping and procrastination, and suggested that the personality-coping-outcome theory can explain the mechanism that links the three variables. By using this theory as a framework, future studies may include other types of personality to examine their relationships with coping and procrastination further.

\section{References}

1. Arslan, C., Dilmaç, B. \& Hamarta, E. (2009). Coping with stress and trait anxiety in terms of locus of control: A study with Turkish university students. Social Behavior and Personality, 37(6), 791-800. https://doi.org/10.2224/sbp.2009.37.6.791

2. Atibuni, D. Z., Ssenyonga, J., Olema, D. K., \& Kemeza, I. (2017). Locus of control as a predictor of academic attitudes among university students. International Journal of Educational Policy Research and Review, 4(6), 125-137. https://doi.org/10.15739/IJEPRR.17.014

3. Bakar, Z. A., \& Khan, M. U. (2016). Relationships between self-efficacy and the academic procrastination behaviour among university students in Malaysia: A general perspective. Journal of Education and Learning, 10(3), 265-274. https://doi.org/10.11591/edulearn.v10i3.3990

4. Baumstarck, K., Alessandrini, M., Hamidou, Z., Auquier, P., Leroy, T., \& Boyer, L. (2017). Assessment of coping: A new French four-factor structure of the brief COPE inventory. Health and Quality of Life Outcomes, 15(1), 8. https://doi.org/10.1186/s12955-016-0581-9

5. Beutel, M. E., Klein, E. M., Aufenanger, S., Brähler, E., Dreier, M., Müller, K. W., Quiring, O., Reinecke, L., Schmutzer, G. \& Stark, B. (2016). Procrastination, distress and life satisfaction 
across the age range-a German representative community study. PloS One, 11(2), e0148054. https://doi.org/10.1371/journal.pone.0148054

6. Boysan, M. \& Kiral, E. (2017). Associations between procrastination, personality, perfectionism, self-esteem and locus of control. British Journal of Guidance \& Counselling, 45(3), 284-296. https://doi.org/10.1080/03069885.2016.1213374

7. Carden, R., Bryant, C. \& Moss, R. (2004). Locus of control, test anxiety, academic procrastination, and achievement among college students. Psychological Reports, 95(2), 581582. https://doi.org/10.2466/pr0.95.2.581-582

8. Carver, C. S. (1997). You want to measure coping but your protocol' too long: Consider the brief cope. International Journal of Behavioral Medicine, 4(1), 92-100. https://doi.org/10.1207/s15327558ijbm0401_6

9. Chun Chu, A. H. \& Choi, J. N. (2005). Rethinking procrastination: Positive effects of" active" procrastination behavior on attitudes and performance. The Journal of Social Psychology, 145(3), 245-264. https://doi.org/10.3200/SOCP.145.3.245-264

10. Craig, A. R., Franklin, J. A. \& Andrews, G. (1984). A scale to measure locus of control of behaviour. British Journal of Medical Psychology, 57(2), 173-180. https://doi.org/10.1111/j.2044-8341.1984.tb01597.x

11. DeMello, L. R., \& Imms, T. (1999). Self-esteem, locus of control and coping styles and their relationship to school attitudes of adolescents. Psychological Studies. https://psycnet.apa.org/record/1999-03991-001

12. Demir, S., Demir, S. G., Bulut, H., \& Hisar, F. (2014). Effect of mentoring program on ways of coping with stress and locus of control for nursing students. Asian Nursing Research, 8(4), 254 260. https://doi.org/10.1016/j.anr.2014.10.004

13. Duru, E. \& Balkis, M. (2017). Procrastination, self-esteem, academic performance, and wellbeing: A moderated mediation model. International Journal of Educational Psychology: IJEP, 6(2), 97-119. https://doi.org/10.17583/ijep.2017.2584

14. Ferrari, J. R. \& Díaz-Morales, J. F. (2014). Procrastination and mental health coping: A brief report related to students. Individual Differences Research, 12(1), 8-11. https://www.academia.edu/download/38109437/555f7bb708ae9963a118b315.pdf2015101063298-10ttc7o.pdf

15. Ferrari, J. R., Parker, J. T. \& Ware, C. B. (1992). Academic procrastination: Personality correlates with Myers-Briggs types, self-efficacy, and academic locus of control. Journal of Social Behavior \& Personality. https://psycnet.apa.org/record/1993-15437-001

16. Gallagher, D. J. (1996). Personality, coping, and objective outcomes: Extraversion, neuroticism, coping styles, and academic performance. Personality and Individual Differences, 21(3), 421429. https://doi.org/10.1016/0191-8869(96)00085-2

17. Gareau, A., Chamandy, M., Kljajic, K. \& Gaudreau, P. (2019). The detrimental effect of academic procrastination on subsequent grades: The mediating role of coping over and above past achievement and working memory capacity. Anxiety, Stress, \& Coping, 32(2), 141-154. https://doi.org/10.1080/10615806.2018.1543763

18. Gargari, R. B., Sabouri, H. \& Norzad, F. (2011). Academic procrastination: The relationship between causal attribution styles and behavioral postponement. Iranian Journal of Psychiatry and Behavioral Sciences, 5(2), 76. https://www.ncbi.nlm.nih.gov/pmc/articles/pmc3939975/

19. Hadi, N. U., Abdullah, N. \& Sentosa, I. (2016). Making sense of mediating analysis: A marketing perspective. Review of Integrative Business \& Economics Research, 5(2), 62-76. https://search.proquest.com/openview/05774f1057d04789954eeb3d9338911e/1?pqorigsite $=$ gscholar $\& \mathrm{cbl}=2032316$

20. Hair Jr, J. F., Hult, G. T. M., Ringle, C. \& Sarstedt, M. (2016). A primer on partial least squares structural equation modeling (PLS-SEM). Sage Publications. https://doi.org/10.15358/9783800653614

21. He, S. (2017). A Multivariate investigation into academic procrastination of university students. Open Journal of Social Sciences, 5(10), 12. https://doi.org/10.4236/jss.2017.510002

22. Jiao, Q. G., DaRos-Voseles, D. A., Collins, K., \& Onwuegbuzie, A. J. (2011). Academic procrastination on the performance of graduate-level cooperative groups in research methods courses. Journal of the Scholarship of Teaching and Learning, 119-138. https://scholarworks.iu.edu/journals/index.php/josotl/article/download/1807/1804

23. Kandemir, M., İlhan, T., Özpolat, A. R. \& Palanc1, M. (2014). Analysis of academic selfefficacy, self-esteem and coping with stress skills predictive power on academic procrastination. Educational Research and Reviews, 9(5), 146-152. https://doi.org/10.5897/ERR2014.1763 
24. Kazemi, M., Zandi, H. G. \& Torabi, F. (2015). The relationship between locus of control with coping styles of problem-focused, excited-focused and avoidance among volleyball young men, Karaj City, Iran. Research Journal of Sport Sciences, 3(11), 290-295. http://rjssjournal.com/wpcontent/uploads/paper70.pdf

25. Kim, H. -Y. (2013). Statistical notes for clinical researchers: Assessing normal distribution (2) using skewness and kurtosis. Restorative Dentistry \& Endodontics, 38(1), 52-54. https://doi.org/10.5395/rde.2013.38.1.52

26. Kurtović, A., Vuković, I., \& Gajić, M. (2018). The effect of locus of control on university students' mental health: Possible mediation through self-esteem and coping. The Journal of Psychology, 152(6), 341-357. https://doi.org/10.1080/00223980.2018.1463962

27. Lazarus, R. S., \& Folkman, S. (1984). Stress, appraisal, and coping. Springer Publishing Company.

28. Leontopoulou, S. (2006). Resilience of Greek youth at an educational transition point: The role of locus of control and coping strategies as resources. Social Indicators Research, 76(1), 95126. https://doi.org/10.1007/s11205-005-4858-3

29. Makola, S. (2014). The importance of a sense of meaning in higher education: Review of literature studies. Journal of Educational Sciences \& Psychology, 4(2), 37-45.

30. Moradi, S., Rashidi, A. \& Golmohammadian, M. (2017). The effectiveness of positive thinking skills on academic procrastination of high school female students Kermanshah City. Interdisciplinary Journal of Virtual Learning in Medical Sciences, 8(1), 1-7. https://doi.org/10.5812/ijvlms.11784

31. Morris, P. E., \& Fritz, C. O. (2015). Conscientiousness and procrastination predict academic coursework marks rather than examination performance. Learning and Individual Differences, 39, 193-198. https://doi.org/10.1016/j.lindif.2015.03.007

32. Onwuegbuzie, A. J. (2004). Academic procrastination and statistics anxiety. Assessment \& Evaluation in Higher Education, 29(1), 3-19. https://doi.org/10.1080/0260293042000160384

33. Parker, J. D. \& Endler, N. S. (1992). Coping with coping assessment: A critical review. European Journal of Personality, 6(5), 321-344. https://doi.org/10.1002/per.2410060502

34. Popa, N. L. (2012). Academic attributions and school achievement among Romanian children left behind by migrant parents. Journal of Educational Sciences \& Psychology, 2(1), 10-18.

35. Popoola, B. I. (2005). A study of procrastinatory behaviour and academic performance of undergraduate students in South Western Nigeria. Journal of Social Sciences, 11(3), 215-218. https://doi.org/10.1080/09718923.2005.11892516

36. Rotter, J. B. (1966). Generalized expectancies for internal versus external control of reinforcement. Psychological Monographs: General and Applied, 80(1), 1. https://doi.org/10.1037/h0092976

37. Saplavska, J. \& Jerkunkova, A. (2018). Academic procrastination and anxiety among students. Engineering For Rural Development, 1192-1196. https://doi.org/10.22616/ERDev2018.17.N357

38. Scott, S. L., Carper, T. M., Middleton, M., White, R., Renk, K. \& Grills-Taquechel, A. (2010). Relationships among locus of control, coping behaviors, and levels of worry following exposure to hurricanes. Journal of Loss and Trauma, 15(2), 123-137. https://doi.org/10.1080/15325020902925985

39. Shahram, V. (2011). Canonical correlation analysis of procrastination, learning strategies and statistics anxiety among Iranian female college students. Procedia-Social and Behavioral Sciences, 30, 1620-1624. https://doi.org/10.1016/j.sbspro.2011.10.314

40. Siah, P. C., Ng, A. H. W., Dharmaraj, E., Foo, C., Tan, S. M. \& Walton Wider. (2019). Grit personality as a mediator or moderator for the effects of internet addiction on procrastination. Journal of Institutional Research South East Asia, 17, 18-32. http://www.seaairweb.info/journal/JIRSEA_v17_n2_2019.pdf\#page=28

41. Sirois, F. M. (2007). "I'll look after my health, later": A replication and extension of the procrastination-health model with community-dwelling adults. Personality and Individual Differences, 43(1), 15-26. https://doi.org/10.1016/j.paid.2006.11.003

42. Sirois, F. M. \& Kitner, R. (2015). Less adaptive or more maladaptive? A meta-analytic investigation of procrastination and coping. European Journal of Personality, 29(4), 433-444. https://doi.org/10.1002/per.1985

43. Sirois, F. M., van Eerde, W. \& Argiropoulou, M. I. (2015). Is procrastination related to sleep quality? Testing an application of the procrastination-health model. Cogent Psychology, 2(1), 1074776. https://doi.org/10.1080/23311908.2015.1074776 
44. Sirois, F., \& Pychyl, T. (2013). Procrastination and the priority of short-term mood regulation: Consequences for future self. Social and Personality Psychology Compass, 7(2), 115-127. https://doi.org/10.1111/spc3.12011

45. Steel, P. (2007). The nature of procrastination: A meta-analytic and theoretical review of quintessential self-regulatory failure. Psychological Bulletin, 133(1), 65. https://doi.org/10.1037/0033-2909.133.1.65

46. Sullivan, G. M. \& Feinn, R. (2012). Using effect size - Or why the P value is not enough. Journal of Graduate Medical Education, 4(3), 279-282. https://doi.org/10.4300/JGME-D-1200156.1

47. Tice, D. M., \& Baumeister, R. F. (1997). Longitudinal study of procrastination, performance, stress, and health: The costs and benefits of dawdling. Psychological Science, 8(6), 454-458. https://doi.org/10.1111/j.1467-9280.1997.tb00460.x

48. Tuasikal, R. F., \& Patria, B. (2019). Role of social support and self-concept clarity as predictors on thesis writing procrastination. Journal of Psychology and Instruction, 3(3), 76-82. https://ejournal.undiksha.ac.id/index.php/JoPaI/article/view/23169

49. Tuckman, B. W. (1991). The development and concurrent validity of the procrastination scale. Educational and Psychological Measurement, 51(2), 473-480. https://doi.org/10.1177/0013164491512022

50. Yurtseven, N., \& Dogan, S. (2019). Structural relationships among academic procrastination, academic motivation, and problem solving skill in prep class college students. Pegem Journal of Education and Instruction, 9(3), 849-876. https://doi.org/10.14527/pegegog.2019.027

51. Zhang, Y., Dong, S., Fang, W., Chai, X., Mei, J., \& Fan, X. (2018). Self-efficacy for selfregulation and fear of failure as mediators between self-esteem and academic procrastination among undergraduates in health professions. Advances in Health Sciences Education, 23(4), 817-830. https://doi.org/10.1007/s10459-018-9832-3 